\title{
The Measurement of Joint Mechanics and their Role in Osteoarthritis Genesis and Progression
}

\author{
David R. Wilson, DPhil
}

\author{
Associate Professor, Department of Orthopaedics and Centre for Hip Health and Mobility, \\ University of British Columbia and \\ Vancouver Coastal Health Research Institute
}

Emily J. McWalter, PhD

Department of Radiology

The Lucas Center for MR Spectroscopy and Imaging

P064-1201 Welch Road

Stanford, CA 94305-5488, United States of America

\author{
James D Johnston, PhD \\ Assistant Professor \\ Department of Mechanical Engineering \\ University of Saskatchewan \\ Saskatoon, SK \\ Canada
}



Address for Proofs and Reprints:

David R. Wilson, DPhil

UBC Orthopaedics

Room 3114, 910 West 10th Ave.

Vancouver, BC

V5Z 4E3

Canada

phone: 6046752584

email: david.wilson@ubc.ca

This work was supported by grants from the Canadian Institute for Health Research (Operating Grant MOP-106680), the Canadian Arthritis Network (Network of Centres of Excellence) and the Natural Sciences and Engineering Research Council of Canada. The authors are grateful to Dr. Michael Hunt (Department of Physical Therapy, University of British Columbia) and Dr. Angela Kedgley (Department of Bioengineering, Imperial College London, UK) for their valuable contributions to this article.

Keywords: osteoarthritis, biomechanics, knee, hip, kinematics 


\section{Introduction}

There is little doubt that mechanics play a role in the initiation, progression and successful treatment of osteoarthritis. However, we don’t yet know enough about which specific mechanical parameters are most important and what their impact is on the disease process to make comprehensive statements about how mechanics should be modified to prevent, slow or arrest the disease process. The idea of a mechanical role in OA is often made clear to the patient: OA is “wear and tear” arthritis, and joint surfaces need to be replaced due to wear in advanced stages of the disease, much like bearing surfaces in an engine that have worn down after too many revolutions. The parallels with machines are sometimes (at least superficially) obvious: obese people load their joints more and have a higher prevalence of OA, which seems analogous to higher loads on a bearing increasing the rate of wear on its surfaces, a well-known mechanical phenomenon. High enough loads can destroy any tissue, so it seems clear that there is a level of joint loading that can injure cartilage irreversibly, leading to erosion from the joint surface. However, the utility of drawing parallels with machines is limited. Cartilage, though avascular and aneural, is a living tissue with capacity to adapt to its mechanical environment - it endures apparently unscathed through the most active decades of life in most people. Currently, many surgical procedures and other treatment and prevention approaches are based implicitly or explicitly on the assumption that they improve or correct joint mechanics, and that his improvement or correction is required to protect the joint from OA. Justifying and improving mechanically-based treatment and prevention approaches requires a critical understanding of the methods used to study joint mechanics and the current evidence for the role of mechanics in OA. The objectives of this review are: 1) to summarize methods for assessing joint mechanics and their relative merits and limitations 2) to describe current evidence for the role of mechanics in OA 
initiation and progression, and 3) to describe some current treatment approaches that focus on modifying joint mechanics. 


\section{Mechanical hypotheses about osteoarthritis}

Many of the hypotheses proposed to explain why OA begins and progresses center on mechanics. The most prevalent and best-researched hypothesis regarding OA pathogenesis is that acute trauma destroys chondrocytes and disrupts the extracellular matrix, resulting in proteoglycan depletion, cartilage breakdown and subsequent $\mathrm{OA}^{1,2}$. Surface damage, proteoglycan loss ${ }^{3}$, and chondrocyte death ${ }^{1}$ are seen commonly in OA, and similar observations have been made with in vitro impact studies on human and animal specimens ${ }^{4-}$

${ }^{6}$. Recent research suggests that even moderate loading can induce biological damage at levels well below those required to produce detectable macroscopic damage, and could be an early event in OA pathogenesis ${ }^{7}$. Prolonged exposure to overloading due to obesity ${ }^{8}$ and/or altered joint mechanics ${ }^{9,10}$ are also hypothesized to be detrimental to long-term joint health.

Altered kinematics and associated increased shear stress, in particular, is believed to be a key initiating factor explaining idiopathic forms of $\mathrm{OA}^{10}$. In the articulating joint, cartilage is exposed to compressive loading (tending to compress the cartilage) and simultaneous shear loading (tending to deform the cartilage) as the two cartilage surfaces slide relative to one another. Abnormal motion (perhaps due to an ACL injury, joint laxity or aging) results in a shift in the region of loading to a cartilage zone not conditioned to frequent load bearing ${ }^{10}$. This shift results in cartilage fibrillation at the cartilage surface-an observation commonly seen in early stages of $\mathrm{OA}^{11,12}$. Following fibrillation there is an increase in friction which will increase the tangential shear load at the cartilage surface, resulting in increased shear stress in the collagen network and further fibrillation. Importantly, cartilage metabolic activity is dependent upon the type of loading (e.g., hydrostatic compression, shear) and exhibits a particularly negative response to excessive shear stress ${ }^{13,14}$. Due to fibrillation, friction, and increased shear stresses, there is a metabolic upregulation of catabolic factors detrimental to cartilage health (e.g., matrix metalloproteinase and interleukins ${ }^{13,14}$ ), resulting in further cartilage degeneration ${ }^{10}$. 
Another hypothesis is that OA progresses due to mechanical changes in subchondral bone $^{15}$. Proponents speculate that, due to impulse loading (loading that changes rapidly over time) and cumulative trauma, microfractures are created in the trabeculae which are repaired by fracture callus. As the trabeculae become thicker and new trabeculae are added, the repair process stiffens the subchondral bone, in effect acting as a support for the endplate. This causes the subchondral region to become less compliant, resulting in increased cartilage stresses and eventual degradation ${ }^{16,17}$. Variable subchondral bone stiffening across the joint surface will also result in stiffness gradients and subsequent increased cartilage shear stresses ${ }^{15}$. A more recent, and generally accepted hypothesis speculates that microfractures within the subchondral cortical endplate (as opposed to adjacent trabeculae), result in subchondral thickening. These microfractures, attributed to impulse loading and repetitive stress, are hypothesized to increase biological activity at the site of injury and result in increased bone turnover and reactivation of the secondary center of ossification, resulting in subchondral thickening, cartilage thinning and increased cartilage stresses ${ }^{18}$. While evidence is emerging from animal studies in support of some of these hypotheses, very little work has been done in humans. Studies are emerging that examine the role of bone in OA using traditional bone mineral density measures. For example, cartilage thinning correlates with bone structure losses in the contralateral compartment in subjects with tibiofemoral osteoarthritis ${ }^{19}$. Ratios of medial to lateral compartment bone mineral density (BMD) have also been associated with compartmental tibiofemoral osteoarthritis ${ }^{20}$. In particular, higher BMD in the medial compartment was associated with medial joint space narrowing and medial sclerosis and higher BMD in the lateral compartment was associated with lateral joint space narrowing and lateral sclerosis ${ }^{20}$. Improved tools for measuring bone, cartilage and joint mechanics may ultimately allow us to test these and other hypotheses in vivo in humans. 


\section{Methods for assessing joint mechanics}

The challenges of study design

It is difficult to test hypotheses about the role of mechanics in OA initiation and progression and the effects of a change in mechanics on OA because appropriate in vivo human studies present major challenges. First, studies require a well-characterized population that has or is at risk for OA, and such populations can be difficult to identify. Large populations are generally needed for studies to have appropriate statistical power, which adds to the cost of and difficulty of managing the study. Second, studies require a means of assessing OA incidence or progression. Radiographic measurements of OA (eg Kellgren-Lawrence grade ${ }^{21}$ ) are often insensitive to early OA and to small increments of progression. More recently advanced MRI techniques have shown some potential for more sensitive, quantitative measurement of OA progression ${ }^{22}$, but these measures are more time-consuming and expensive than radiographic approaches and they have not often been used in conjunction with mechanical assessments. Finally and most critically, such studies require in vivo assessments of joint mechanics. Standard clinical measurements used as surrogates for mechanics have been used in a number of studies, but they have many limitations. More advanced mechanical measurement methods have been developed, but studies have generally only been done in small populations because the measurements are expensive and timeconsuming.

What would we like to measure and why can't we do it?

There are a number of hypotheses about the links between mechanics and OA, and these hypotheses define the mechanical quantities of primary interest to researchers. Unfortunately, the most interesting quantities are among the most difficult to measure. Compressive and tangential shear force on the joint surfaces is a key quantity in many hypotheses, but it can only be measured 
directly by implanting a measurement device into the joint, which is far too interventional (in the case of the natural joint) for most in vivo studies of humans. Force distribution on the cartilage surface is also widely believed to be important - a moderate force transmitted through a small contact area may produce local stresses that cause cartilage damage, while the same force transmitted through a large contact area would produce no cartilage injury. While there are sensors available to measure force distribution ${ }^{23}$, they must also be implanted, which carries the same limitations in vivo as direct measurements of force. Loading rate has been postulated to play a role in $\mathrm{OA}^{24}$. Assessing loading rate requires very rapid measurements of force (typically hundreds a second), which is considerably more challenging than static force measurements. There is also substantial interest in how force is transmitted through joint structures such as cartilage and bone (stress). Measuring stress in simple machines and structures is a challenge, and stress has not been measured in joints in vivo. Some approaches are emerging for measuring strain, or deformation of the joint tissues in response to stress ${ }^{25-28}$, but the relationship between stress and strain is much more complex in joint tissues than in, say, steel or glass, which makes it difficult to use strain measurements to predict stress. Kinematics (joint movement) are easier to measure and several methods for accurately quantifying joint kinematics in vivo have been developed in recent years. Kinematics describe how the bones that make up the joint move relative to each other, which can reflect where load is transmitted through the surfaces and the lines of action of structures that transmit forces.

\section{Ex vivo studies and joint models}

Our current understanding of joint mechanics is founded on ex vivo studies, which are inappropriate for linking mechanics with clinical symptoms. In ex vivo studies, kinematics and contact mechanics have been measured in cadaver specimens loaded in mechanical rigs ${ }^{29-34}$ 35,36. 
While studies of this type have helped us to understand biomechanics of healthy joints, their central limitation for studying OA is that morphological adaptations due to the disease process or the healing process and mechanical links to clinical symptoms such as pain and ongoing processes such as cartilage degeneration cannot be studied in cadavers. An alternative, which avoids some of the limitations of mechanical measurements that can be made in vivo, is to predict joint mechanics using mathematical models. Models are limited primarily by the assumptions that must be made to formulate them. Models incorporating sophisticated descriptions of joint structures have been developed and validated ${ }^{37,38,39-42}$ and used to answer specific clinically-motivated questions ${ }^{43-47}$. Two primary limitations of mathematical models are that a) many simplifying assumptions must be made about the properties of the joint, which limits their validity and applicability and b) like ex vivo studies, they are inappropriate for studying links with ongoing in vivo symptoms and processes, unless these changes are measured and incorporated into the model.

Subject-specific finite element (FE) modeling is an emerging technique in musculoskeletal research which has potential for shedding light on the role of mechanics in OA initiation and progression ${ }^{48}$. FE modeling is a computational engineering technique used to evaluate how a structure with complex geometry composed of a range of materials behaves when subjected to loading. Its basic premise is to divide a complicated object into a finite number of small manageable pieces (elements). The behavior of each element can be described mathematically and evaluated computationally ${ }^{49}$. Using clinical CT or MRI, a joint's bone, cartilage, and soft tissue geometry can be acquired. Tissue material properties (e.g., elastic modulus, stiffness) can also be estimated using CT or MRI ${ }^{50,51}$. Image-derived geometry and material properties can then be used to create a subject-specific FE model, which can be analyzed under varying loading scenarios (e.g., repetitive walking, impact intensive running) to simulate bone and cartilage responses to loading. Importantly, unique information impossible to measure experimentally (e.g., internal stress and strain distributions in both bone and cartilage) can be acquired using FE modeling and linked with in vivo symptoms and OA processes. The FE method can also be applied longitudinally to evaluate 
bone and cartilage structural behavior following OA-related morphological and mechanical alterations to these tissues. However, application of subject-specific FE modeling to address OA-related questions is in its infancy. To date, research employing subject-specific FE modeling has been primarily restricted to addressing osteoporosis-related research questions (e.g., fracture strength) of bony structures not

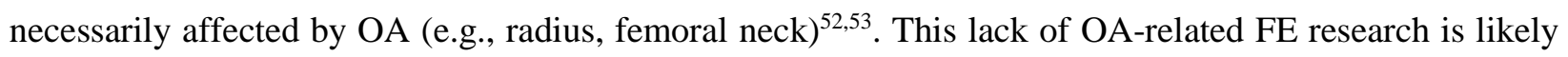
due to difficulties associated with validating FE models comprised of numerous complex joint tissues. For example, it is impossible to place a device for measuring strain (i.e., a strain-gauge) in cartilage or in trabecular bone adjacent to overlying cartilage. Recently, however, new methods have been developed ${ }^{26,54}$ which have potential to validate internal strain distributions in bone and cartilage acquired using FEmodeling, and can be applied using intact joints. These developments, combined with improvements in CT and MRI technologies and computing power, have made subject-specific FE modeling a candidate technique for addressing specific questions regarding the role of mechanics in OA initiation and progression.

\section{Radiographic measures of alignment}

Most of the measures used clinically to quantify joint mechanics assess joint alignment. For example, tibiofemoral alignment is often quantified with the femorotibial angle, or hip-knee-ankle angle $^{55}$. A range of measures has emerged for quantifying patellofemoral alignment, with particular emphasis on medial-lateral position and patellar tilt. A central limitation of this approach is that the measures describe the joint (whose primary function is to move) at only one static position. In addition, while it is intuitive that these alignment measures are related to how load is transmitted in the joint, it is important to note that for most measures it is unclear how any given change in alignment measure would change force distribution in the joint. A further limitation is that the accuracy and repeatability of these measures is affected by their twodimensional nature. Two-dimensional radiographic measurements are prone to errors due to 
magnification and subject positioning. MRI and CT collect three dimensional information about joint anatomy, which has been used in such applications as quantifying femoral neck deformities thought to be associated with hip osteoarthritis ${ }^{56}$. In many cases, however, the three-dimensional data are still reduced to a two-dimensional measurement, which does not describe threedimensional deformities adequately.

\section{Gait analysis}

Gait analysis (often more generally referred to as “'motion analysis”) is an important modality for estimating joint mechanics in activity. In motion analysis, movement of the joint segments is tracked (most often with an optoelectronic system), and loads applied to the body (eg, groundreaction forces) are measured. Mechanical analysis then can be used to assess the resultant forces and moments at the joints for each position where a complete set of measurements is available. It is essential to note that the resultant forces and moments at the joints, which are output by the majority of commercial motion analysis systems, are entirely different from the contact forces (also known as the bone-on-bone forces) in the joint. Determining contact forces requires further analysis using joint models ${ }^{57}$ and the measured joint segment positions and loads applied to the body. One advantage of gait analysis is that movement is relatively unconstrained by the measurement system, and therefore a large range of activities can be studied. One key limitation of gait analysis is that joint segments are typically tracked with markers fixed to the skin, which moves substantially relative to the bones. However, it is often difficult to identify the joint centre (or axis of rotation), particularly at the hip, and it is difficult to assess how well the measured marker positions correspond to motion at the joint (differences have been found to be on the order of 10 degreees for knee flexion ${ }^{58}$ ). The use of large groups of skin-mounted markers has reduced the error caused by skin movement ${ }^{59}$. A second key limitation is that the models and analysis 
needed to determine joint contact forces require many simplifications and assumptions, limiting the accuracy with which these loads can be measured ${ }^{60}$. Often models have been based on the anatomy of a single specimen or participant, as opposed to using subject-specific anatomical measurements. This limits the usefulness of these models ${ }^{61}$, particularly when pathologic joints are involved.

Roentgen stereophotogrammetric analysis and in vivo radiography

Some of the limitations of motion analysis have been addressed with radiography-based methods for measuring motion including roentgen stereophotogrammetric analysis (RSA, alternately known as radiostereometric analysis) and fluoroscopy. Three-dimensional knee kinematics have been measured during activity in vivo using single-plane fluoroscopy and subsequent image processing. This measurement has been done in joints after arthroplasty ${ }^{62}$ and in natural joints ${ }^{63}$. A limitation of the single-plane approach is that measurement errors out of the imaging plane are quite large. More accurate three-dimensional measurements of kinematics can be made with biplanar fluoroscopy ${ }^{64}$ and biplanar radiography, which has been used to study kinematics in the knees ${ }^{65,66}$, hip ${ }^{67}$, shoulder ${ }^{68}$ and other joints. Although many biplanar radiography studies are done using a series of static positions, high-speed biplanar radiography has made possible accurate measurements of kinematics during dynamic activity ${ }^{69,70}$. Because these measurements are so accurate, combining kinematics with known joint geometry yields predictions of joint-contact interactions ${ }^{67,71}$. In some approaches, markers (typically small tantalum spheres) have been implanted into the bones, an invasive procedure, which is a clear limitation. However, recent work using model-based approaches suggests that measurements can be made accurately and precisely enough to be clinically useful without using implanted markers ${ }^{67,72,73}$. A key limitation of all these approaches is that they expose patients to ionizing 
radiation. Radiation doses vary dramatically with the joint of interest and the size of the subject. Such exposure always carries some risk and limits the number of repeat assessments that can be made, although in general imaging of the extremities is less of a concern than whole body imaging because the body core can be shielded from radiation.

\section{MRI measurements of kinematics}

MRI has been used to assess joint kinematics and has the advantages that soft tissues are easily visualized and that no ionizing radiation is required, making it ideal for use in longitudinal studies. The different MRI-based approaches for assessing kinematics are distinguished from one another other by whether they describe two-dimensional or three-dimensional movement, whether they are assessed while the joint is actively loaded, and whether the movement is measured continuously. To date, most MRI studies of kinematics have focused on the patellofemoral joint, largely because patellar tracking is difficult to measure with other techniques such as gait analysis due to difficulties tracking skin-mounted markers on this small bone. Two-dimensional techniques have been used to assess kinematics at sequential static angles of knee flexion, dynamically over a range of knee flexion, unloaded and loaded in a supine, lateral or standing position ${ }^{74-79}$. Loading

in the supine or lateral position is carried out by applying, respectively, an axial force to the foot or a torsional load to the shank using custom designed rigs. The primary limitation of twodimensional studies is that they neglect at least half of the movement, because describing any joint's movement completely requires six quantities of movement (typically three rotations and three translations ${ }^{78,80}$. Planar studies can measure a maximum of three quantities.

Three-dimensional MRI-based kinematic methods, which measure the six quantities of movement, have also been developed and fall under similar categories to two-dimensional 
techniques (sequential static vs dynamic, unloaded vs loaded) ${ }^{81-91}$. The static three-dimensional methods have employed standard MRI sequences whereas the dynamic methods have employed ultrafast gradient echo ${ }^{85}$, cine-MRI ${ }^{86-89,92,93}$, phase-contrast MRI $^{90}$ and spoiled gradient echoes with radial acquisitions ${ }^{84}$. Although promising, these techniques have some limitations; most notably that static postures in a supine position do not necessarily represent normal activities of daily living, and dynamic methods either require subjects to extend their knee very slowly, which is not necessarily representative of normal motion, or flex and extend their knees through many cycles which are averaged, which can cause errors if the motion is repeated perfectly between cycles. Accuracy of these techniques ranges from approximately $1 \mathrm{~mm}$ and $1^{\circ} 81,82$ up to approximately $2 \mathrm{~mm}$ and $3^{\circ}{ }^{94}$. Clinically important differences are likely within this range. It should be noted that not all techniques have been rigorously validated and, therefore, care should be taken when interpreting data.

There are inherent tradeoffs between static and dynamic methods and loaded and unloaded methods, as well as noteworthy limitations to these techniques. Substantial differences in twodimensional patellar kinematic measures have been observed between unloaded, sequential static assessments and unloaded, dynamic assessments ${ }^{74}$. Similarly, substantial differences were observed between static, loaded assessments and dynamic, loaded assessments in a threedimensional analysis ${ }^{85}$. These results suggest that differences exist between the static and dynamic case, regardless of applied load. To further support this, two other studies have shown differences in two-dimensional patellar kinematics assessed dynamically between a supine low-load scenario and an upright $45 \%$ bodyweight scenario ${ }^{95}$ and in three-dimensional patellar kinematics assessed statically in the supine position at $0 \%, 15 \%$ and $30 \%$ bodyweight scenario ${ }^{96}$. It should be noted that most methods apply relatively low loads to the limb (0-50\% bodyweight load, open- and 
closed-chain), which is due to the limitations of loading the leg in the close bore MRI scanner. While open-configuration MRI allows greater loads to be applied (at least $45 \%$ bodyweight in weightbearing) because the subject can stand upright, these scanners have lower field strengths, limiting image quality and increasing scan times, and are not widely available. The range of flexion angles that can be studies is also limited by the MRI scanner configuration; flexion angles of up to approximately $40^{\circ}$ or $50^{\circ}$, depending on knee size, can be assessed in the closed bore systems while angles of $60^{\circ}$ and above can be assessed in open-configuration scanners. In addition to these differences, the definition of the kinematic quantities themselves differ greatly between studies. This makes comparing results between studies challenging. A final limitation is that most of this work has focused on the knee; few data are available for kinematics of the hip, shoulder, elbow, or hand.

\section{MRI measurements of contact area}

Joint contact areas are fundamental to the understanding of load transmission through the joint and its relationship to local degeneration in OA. Ideally we would measure contact areas, contact loads, contact stresses and tissue stresses. However, currently the only in vivo measure possible is contact area. Direct measures of contact area can only be made with MRI. Contact area measurements are useful because they provide information about where loads are transmitted on the cartilage surface and they can be used to find average contact stress (if joint loads can be estimated). Several groups have developed methods of assessing contact area in vivo from $\mathrm{MRI}^{75,79,83,97-114}$. All of these methods have used gradient echo techniques with fat suppression, which is optimized to view cartilage. These scans have been acquired using traditional scanners 
(1.5 and 3.0T) and open configuration scanners (0.5T) using the loading methods similar to those employed for kinematic assessments. Contact area is generally assessed at sequential static, loaded angles of knee flexion, although it was measured during continuous flexion in a recent study ${ }^{109}$. Axial and sagittal scans have been used; the choice of plane should be based on the one that provides the most information about the contact periphery. Once the MRI scans are acquired, they must be processed to calculate contact areas. This can be done by delineating the contact region in a slice-by-slice manner and multiplying the length of each contact line and by slice thickness ${ }^{75,97-99,103-105}$ or interpolating between slices and summing the areas of discrete patches 83,102,107. Alternatively, adjacent cartilage plates can be segmented separately and contact can then either expanding one surface by a pixel and defining overlap as contact ${ }^{79,100,101}$ or carrying out a proximity analysis ${ }^{106}$. The coordinates of the contact centroid have also been reported on occasion $^{83,107,115}$; these may provide valuable information about changes in contact location and are most useful when reported in a relevant coordinate system, such as that used for kinematic assessment. Validation of MRI-based techniques has been limited; only three studies that have examined agreement with a reference standard, two using cadaver specimens ${ }^{99,116}$ and the other using a phantom ${ }^{98}$. Errors, expressed as coefficient of variation were found to be $11 \%, 13 \%$ and 3\%, respectively. Intra-observer, inter-observer and intra-subject repeatability has also been assessed in vivo and have ranged from $3 \%$ to $10 \%^{79,98,103,116}$. Many of the factors that affect measures of patellar kinematics, such as loading, range of motion and tibiofemoral angle, are equally applicable to measures of contact area. Most studies have focused on the patellofemoral joint $^{75,79,83,97-105,107,108,111,112,115}$, while others have examined contact areas in the elbow ${ }^{108,117,118}$ and tibiofemoral joint ${ }^{110,113,114}$. Little or no work has addressed the hip, shoulder, wrist, or hands. 


\section{The future}

Technologic advances hold promise for more and better in vivo mechanical measurements. Many of the methods described in this article are now beginning to be used to study patient populations. One area with promise is MRI mapping of cartilage strain, which had been done ex vivo in the knee $^{25,119,120}$ and the hip ${ }^{121}$. This work is challenging because achieving the resolution required to detect small changes in cartilage thickness in a short imaging time requires very high field strength scanners. As these scanners becoming more widely available for clinical use, there is potential to begin assessments of strain in vivo. Groups are also beginning to integrate mechanical measures with other OA disease indicators. For example, a recent study combined measures of contact area with measures of T1rho and T2 relaxometry; individuals with OA had longer T1rho and T2 relaxation times and greater contact areas ${ }^{111}$. Integration of mechanical measurements with MR techniques that aim to detect early degenerative changes may be very useful for improving our understanding of the etiology of OA. CT technology is also improving, with scans becoming very fast and requiring relatively small doses of ionizing radiation. This raises the possibility of wider use of CT to assess joint kinematics and other mechanical quantities as well as integrating these measures with radiographic and MRI-based measures of tissue degeneration and OA. Finally, developments in nanotechnology suggest the feasibility of developing implantable transducers that transmit measurements through telemetry; this has been done on a limited scale ${ }^{122}$ but as technology improves may become more widespread. 


\section{Current evidence for the role of mechanics in OA initiation and progression}

\section{Distinction between normal aging and $O A$}

We often think of OA as a disease of aging that is mechanical in origin ${ }^{123}$; however, it is likely that there are some changes in mechanics over time that are a result of normal aging and not necessarily the OA disease process. For example, one study found, in participants without radiographic signs of $\mathrm{OA}$, a significant increase in valgus alignment with age at a rate of $0.03^{\circ}$ and $0.04^{\circ}$ per year in males and females, respectively ${ }^{124}$. In the same study, participants with OA tended to show increasing varus angulation. Another study showed, through principal component analysis, that patterns of gait differed between young $(23.9 \pm 2.6$ years $)$ and older (65.5 \pm 5.2 years) participants when climbing stairs ${ }^{125}$. These findings suggest that patterns of changes in joint mechanics may differ not only with OA but also with normal ageing. This highlights the need for establishing age-dependent population norms for studying OA.

\section{Alignment}

Joint malalignment or incongruence leads to altered loading patterns at the cartilage surface, therefore, it is not surprising that joint alignment is associated with OA. Tibiofemoral alignment has been studied extensively in individuals who have tibiofemoral and/or patellofemoral $\mathrm{OA}^{126-131}$. However, this relationship is not necessarily as straightforward as one might expect with one study reporting that tibiofemoral alignment did not predict the incident tibiofemoral OA, suggesting that instead it may be a marker of disease or progression ${ }^{132}$. Another interesting paradigm is that increased body mass index in a risk factor for incident OA but only affected OA progression in knees with moderate malalignment $(\mathrm{OR}=1.23)$, not neutral knees ${ }^{133}$. A subsequent study showed that a high BMI increased risk of OA progression only in neutral and valgus knees 
$(\mathrm{OR}=1.4 \text { ad 1.8, respectively })^{134}$. These results are somewhat conflicting indicating that further examination is necessary. Regardless, it is not surprising that tibiofemoral alignment has also been shown to be protective against cartilage loss in the 'less loaded' compartment, as assessed by MRI, (OR=3.7 and 6.0 for the protected lateral and medial compartment, respectively) $)^{135}$. Tibiofemoral alignment also has been shown to be associated with patellofemoral $\mathrm{OA}^{126,127,130,136 \text { : }}$ varus tibiofemoral malalignment increases the odds of medial compartment radiographic patellofemoral $\mathrm{OA}$ progression $(\mathrm{OR}=1.85)$ and valgus tibiofemoral malalignment increases the odds of lateral compartment patellofemoral OA progression $(\mathrm{OR}=1.64)^{126}$. More recently, the relationship between alignment and cartilage tissue properties, as assessed non-invasively by MRI, has also been studied. For example, joint space narrowing of one compartment was associated with a lower dGEMRIC index (ie less proteoglycan) in that compartmen ${ }^{137}$. Further, T2 relaxation times have also been shown to be elevated in the medial compartment of individuals with varus malalignment ${ }^{138}$. Together, all these data suggest that tibiofemoral alignment plays an important role in OA but, in some instances, this role is one part of a complex interaction with other mechanical risk factors.

Patellar alignment, along with tibiofemoral alignment, plays an important role in patellofemoral OA. Lateral patellar alignment has been associated with lateral joint space narrowing $(\mathrm{OR}=8.26)^{139}$, lateral osteophytes $(\mathrm{OR}=3.07)^{139}$, lateral cartilage loss $(\mathrm{OR}=3.4)^{140}$ and lateral bone marrow lesions $(\mathrm{OR}=3.2)^{141}$. Medial patellar alignment has been associated with medial joint space narrowing $(\mathrm{OR}=2.85)^{139}$. In a study of $\mathrm{OA}$ progression, medial displacement of the patella increased the risk of medial patellofemoral joint space narrowing progression $(\mathrm{OR}=2.2)$, while it was protective of lateral patellofemoral joint space narrowing progression $(\mathrm{OR}=0.4)$ and increasing lateral tilt was protective of medial patellofemoral joint space narrowing progression 
$(\mathrm{OR}=0.2)^{142}$. It has also been shown that patella alta (a high riding patella) is associated with lateral joint space narrowing $(\mathrm{OR}=2.77)^{139}$, lateral osteophytes $(\mathrm{OR}=1.67)^{139}$, medial and lateral cartilage loss (OR=2.0-2.4 and 1.5- 2.0, respectively) ${ }^{140,143}$ and medial and lateral bone marrow lesions (OR=2.5-2.9) ${ }^{140,143}$ and medial and lateral subchondral bone attrition $(\mathrm{OR}=2.2$ and -3.5 , respectively $)^{143}$. Interestingly, there is a high prevalence of medial patellofemoral OA that is independent of alignment ${ }^{144}$. This highlights that alignment alone does explain all patellofemoral OA and perhaps more complex techniques, such as assessments of three-dimensional kinematics and contact area may be required to understand the relationship between mechanics and patellofemoral OA.

\section{Other surrogates for high joint forces}

A number of studies have found associations between surrogate measures of high joint forces and OA. As discussed previously, joint forces cannot be measured directly, but estimates based on anthropometry, joint congruency or alignment, gait analysis, and activities of daily living can be used to study the effect of higher joint forces. Several mechanical factors have been associated with radiographic and/or MRI-based definitions of OA such as obesity ${ }^{134,145-147}$, patellar alignment ${ }^{139-141}$, knee height ${ }^{148}$, squatting ${ }^{149}$ and meniscectomy ${ }^{131,150}$. Although, apart from patellar alignment, these are not direct measures of mechanics these associations suggest that mechanics play a role in OA. For example, it is not surprising that knee height, which contributes to increased moments about the knee and associated higher theoretic contact forces in the joints, was associated with an increasing prevalence of symptomatic and radiographic knee $\mathrm{OA}^{151}$. More specifically, increased knee height, measured from the ground to the femoral condyles when sitting, was associated with radiographic patellofemoral $\mathrm{OA}$ in men $(\mathrm{OR}=1.7)$ and was associated with symptomatic patellofemoral $\mathrm{OA}$ in women $(\mathrm{OR}=2.2)^{151}$. Prolonged squatting (which theoretically produces high forces in the knee) in elderly Chinese men was also associated with higher risk for knee $\mathrm{OA}^{149}$. 
Obesity has been identified as a risk factor of both patellofemoral OA and tibiofemoral OA ${ }^{145,146}$. In fact, obesity puts individuals at greater risk of radiographic patellofemoral OA than radiographic tibiofemoral OA (odds ratios $(\mathrm{OR})=3.5,7$ and 1.9 for isolated patellofemoral, combined and tibiofemoral OA, respectively) ${ }^{145}$. Gait analysis is probably the most widely used tool to estimate joint loads in OA. Different aspects of these analyses have been associated with OA. One of the strongest relationships between gait and $\mathrm{OA}$ is that knee adduction moment is associated with $\mathrm{OA}^{152-154}$. A more recent study showed that cumulative knee adductor load was better than the peak knee adduction moment at discriminating between healthy and OA groups ${ }^{155}$. Gait analysis has also revealed that mechanics at other joints such as the hip and ankle can affect OA at the knee. For example, medial tibiofemoral compartment OA is associated with hip adduction moments and higher axial loading rates at the hip, knee, and ankle ${ }^{156}$. Gait parameters at the hip, knee, and ankle also vary, depending on the severity of $\mathrm{OA}^{157}$. It has been suggested that the changes in gait mechanics may be a compensatory mechanism to reduce pain by reducing joint loads at the affected joint ${ }^{158,159} 160$. Asymmetric gait patterns have also been shown in subjects who have advanced hip OA ${ }^{161}$ and in subjects with unilateral knee OA ${ }^{162}$. Interestingly, in the latter study, individuals with bi-lateral OA did not display the same asymmetry in gait patterns. Ankle mechanics have been studied to a lesser extent than knee and hip mechanics, but it has been shown that a greater toe-out angle $^{163}$ and load ${ }^{156}$ is associated with the progression of medial tibiofemoral OA. All these surrogate measures of joint loading provide information about the relative magnitudes of force being transmitted through the joint, but they do not indicate where on the joint surface these loads are transmitted. Advances in weight-bearing imaging may elucidate this point in the future. 
Injury

Joint fractures and acute injury to the menisci, and anterior cruciate ligament are all very clearly associated with the development of osteoarthritis, but the specifics of how injury affects mechanics, and how mechanical changes lead to osteoarthritis, are not clear. Fractures of the joint surface at the hip, knee and ankle are associated with high rates of osteoarthritis, and the development of osteoarthritis is related to elevated contact stress caused by the fracture ${ }^{164}$. Meniscal and anterior cruciate ligament injuries are well known factors in the development of early knee osteoarthritis ${ }^{165}$. $43 \%$ of subjects who had undergone meniscectomy due to meniscal tears had radiographic evidence of osteoarthritis after 16 years ${ }^{166}$, meniscectomy increases risk of developing OA $(\mathrm{OR}=2.6)^{150,167-170}$, 51\% of female soccer players with anterior cruciate ligament (ACL) injury had radiographic evidence of osteoarthritis after 12 years ${ }^{171}$ and $41 \%$ of male soccer players with ACL injury had radiographic evidence of osteoarthritis after 14 years ${ }^{172}$. A study of ACL injury in a population of individuals with symptomatic knee osteoarthritis found that a complete ACL tear increased the risk for medial tibiofemoral cartilage thinning as compared to those with intact ACL or partial ACL tears (odds ratio = 1.8, adjusted for age, body mass index, and gender $)^{173}$. However once an adjustment for medial meniscal tears was included in the regression model, a complete ACL tear was not an independent risk factor of cartilage thinning (odds ratio $=1.1)^{173}$. Bone marrow lesions were associated with ACL tears in the same cohort ${ }^{174}$. While it is clear that these acute injuries are associated with osteoarthritis, and change in joint mechanics produced by the injuries plays a role in the etiology of osteoarthritis, many other factors related to the patient, injury, and treatment will affect whether osteoarthritis develops after injury, and at what rate ${ }^{165}$. Researchers have proposed hypotheses detailing the cascade of events 
involving the effect of ACL injury on knee mechanics, the resulting change in loading patterns and the cartilage response $\mathrm{e}^{175}$.

\section{Deformity}

In contrast with knee OA, hip osteoarthritis is generally associated with either instability or deformity, with primary hip OA considered rare. While the association between severe hip deformity and osteoarthritis has been understood for decades, interest has more recently focused on the role of more subtle deformities. It is well accepted that many cases of "idiopathic" hip osteoarthritis can be attributed to bony deformity ${ }^{176}$. The hypothesis that femoroacetabular impingement (FAI) is a major etiologic factor leading to osteoarthritis has growing support in the orthopaedic literature ${ }^{27,28,177}$. Two mechanisms by which the cartilage and labrum are affected by FAI have been described ${ }^{178}$. Cam impingement is a result of a non-spherical femoral head abutting against the acetabular rim in flexion and internal rotation. The abutment creates shear forces resulting in damage to the anterosuperior acetabular cartilage. Pincer impingement occurs as a result of linear contact between the femoral head-neck junction and the acetabular rim. In support of the FAI hypothesis, many studies have shown associations between features of impingement and cartilage damage. For example, in a study of 149 hips with mild or no radiographic OA, patients with radiological features of cam impingement (26 hips) had damage to the anterosuperior acetabular cartilage, while patients with radiological features of pincer impingement (16 hips) had a narrow strip of circumferential cartilage damage ${ }^{179}$. Specific radiological features predicted progression to hip osteoarthritis (over at least ten years) in patients with a pistol-grip deformity ${ }^{180}$. Early cartilage changes were present in hip cartilage in participants with cam deformities who had 
not complained of osteoarthritic symptoms ${ }^{181}$. The prevalence of cam deformities in young males was reported to be $24 \%{ }^{182}$, and the prevalence of specific cam and pincer deformity signs was higher in men than in women ${ }^{183}$. Although hip deformity appears to be related to osteoarthritis, it is not clear what dictates whether or not FAI deformities will lead to osteoarthritis, how many patients with the symptoms of FAI have cartilage changes, at what stage osteoarthritic changes begin in FAI, and how they progress and whether they can be prevented or reversed. 


\section{The role of mechanics in $\mathrm{OA}$ treatment}

Given the clear role of mechanical factors in OA incidence and progression, it makes sense that some treatment approaches focus on modifying joint mechanics. Approaches include surgery, bracing, wedging, gait modification, walking aids, and muscle stretching and strengthening exercises. Anterior cruciate ligament repair is the treatment of choice for ligament rupture, with the primary justification for the procedure being protection of the joint from OA. Similarly, joint reconstruction including repair of the posterior cruciate ligament, medial collateral ligament, menisci, acetabular labrum and many smaller structures is now widespread, and cartilage repair using grafts or engineered tissue is used to treat small lesions in young patients with traumatic damage to the cartilage. High tibial osteotomy is a surgical procedure used to treat tibiofemoral osteoarthritis associated with abnormal tibiofemoral malalignment. In high tibial osteotomy, a wedge of bone from the proximal tibia is resected (closing-wedge) or added (opening-wedge) to realign the lower limb, placing more force on the lateral compartment of the knee (generally) in an effort to reduce pain and delay cartilage degeneration in the medial compartment ${ }^{184}$. Several groups have reported that high tibial osteotomy either arrests cartilage degeneration ${ }^{185}$ or leads to cartilage regeneration $^{55,186}$ in the diseased compartment. Surgical correction of hip deformity associated with femoroacetabular impingement syndrome improves symptoms in the majority of patients without advanced osteoarthritis or chondral damage in the short term ${ }^{187}$. However the longer term success of these procedures is not clear ${ }^{188}$. Conservative approaches to modify mechanics include gait retraining, bracing, muscle stretching and training and modifying footware with the objective of redistributing forces in the compartments of the knee and using walking aids such as poles and canes to reduce or redistribute load in the knee ${ }^{189}$. 
There is no simple explanation for why more mechanically-based interventions are not being pursued. Weight loss is difficult, and exercise regimens require dedication. Insoles and braces can be uncomfortable and cumbersome. Joint reconstruction surgery aims to protect the joint from osteoarthritis in many instances, but its success is generally judged more on return to joint function in the short term rather than long-term incidence of OA. High tibial osteotomy is technically demanding, requires a relatively long recovery, has yielded only mixed clinical success $^{190,191}$ and has unicompartmental arthroplasty as an appealing alternative. Hip deformity correction is rapidly gaining interest, but is technically demanding. More generally, many surgeons are reluctant to operate on asymptomatic or mildly symptomatic joints, but intervening to restore joint integrity or correct a joint deformity may prove effective at heading off the OA disease process.

\section{Conclusion}

We have learned a lot about the links between mechanics and OA in recent years. We should not be surprised that the findings are not all necessarily straightforward (OA is complex, so are joint biomechanics), nor should we be deterred from pursuing more knowledge in this area. New and better methods for measuring joint mechanics offer substantial promise to accelerate the pace of discovery. There is substantial scope for improving our understanding of mechanically-based treatments for $\mathrm{OA}$ and for developing new ones that better address this prevalent and disabling condition. ${ }^{192}$ 


\section{References}

1. Blanco FJ, Guitian R, Vazquez-Martul E, de Toro FJ, Galdo F. Osteoarthritis chondrocytes die by apoptosis. A possible pathway for osteoarthritis pathology. Arthritis Rheum. Feb 1998;41(2):284289.

2. Aigner T, McKenna L. Molecular pathology and pathobiology of osteoarthritic cartilage. Cell Mol Life Sci. Jan 2002;59(1):5-18.

3. Mankin HJ, Dorfman H, Lippiello L, Zarins A. Biochemical and metabolic abnormalities in articular cartilage from osteo-arthritic human hips. II. Correlation of morphology with biochemical and metabolic data. J Bone Joint Surg Am. Apr 1971;53(3):523-537.

4. Green DM, Noble PC, Ahuero JS, Birdsall HH. Cellular events leading to chondrocyte death after cartilage impact injury. Arthritis Rheum. May 2006;54(5):1509-1517.

5. Huser CA, Davies ME. Validation of an in vitro single-impact load model of the initiation of osteoarthritis-like changes in articular cartilage. J Orthop Res. Apr 2006;24(4):725-732.

6. Whiteside RA, Jakob RP, Wyss UP, Mainil-Varlet P. Impact loading of articular cartilage during transplantation of osteochondral autograft. J Bone Joint Surg Br. Sep 2005;87(9):1285-1291.

7. Nishimuta JF, Levenston ME. Response of cartilage and meniscus tissue explants to in vitro compressive overload. Osteoarthritis Cartilage. May 2012;20(5):422-429.

8. Anderson JJ, Felson DT. Factors associated with osteoarthritis of the knee in the first national Health and Nutrition Examination Survey (HANES I). Evidence for an association with overweight, race, and physical demands of work. Am J Epidemiol. Jul 1988;128(1):179-189.

9. Setton LA, Elliott DM, Mow VC. Altered mechanics of cartilage with osteoarthritis: human osteoarthritis and an experimental model of joint degeneration. Osteoarthritis Cartilage. Jan 1999;7(1):2-14.

10. Andriacchi TP, Mundermann A, Smith RL, Alexander EJ, Dyrby CO, Koo S. A framework for the in vivo pathomechanics of osteoarthritis at the knee. Ann Biomed Eng. Mar 2004;32(3):447-457.

11. Guilak F, Ratcliffe A, Lane N, Rosenwasser MP, Mow VC. Mechanical and biochemical changes in the superficial zone of articular cartilage in canine experimental osteoarthritis. J Orthop Res. Jul 1994;12(4):474-484.

12. Maniwa S, Nishikori T, Furukawa S, Kajitani K, Ochi M. Alteration of collagen network and negative charge of articular cartilage surface in the early stage of experimental osteoarthritis. Arch Orthop Trauma Surg. 2001;121(4):181-185.

13. Lane Smith R, Trindade MC, Ikenoue $T$, et al. Effects of shear stress on articular chondrocyte metabolism. Biorheology. 2000;37(1-2):95-107.

14. Smith RL, Carter DR, Schurman DJ. Pressure and shear differentially alter human articular chondrocyte metabolism: a review. Clin Orthop Relat Res. Oct 2004(427 Suppl):S89-95.

15. Radin EL, Rose RM. Role of subchondral bone in the initiation and progression of cartilage damage. Clin Orthop Relat Res. Dec 1986(213):34-40.

16. Radin EL, Paul IL, Rose RM. Role of mechanical factors in pathogenesis of primary osteoarthritis. Lancet. Mar 4 1972;1(7749):519-522.

17. Radin EL, Parker HG, Pugh JW, Steinberg RS, Paul IL, Rose RM. Response of joints to impact loading. 3. Relationship between trabecular microfractures and cartilage degeneration. J Biomech. Jan 1973;6(1):51-57.

18. Burr DB, Radin EL. Microfractures and microcracks in subchondral bone: are they relevant to osteoarthrosis? Rheum Dis Clin North Am. Nov 2003;29(4):675-685. 
19. Lindsey $\mathrm{CT}$, Narasimhan A, Adolfo JM, et al. Magnetic resonance evaluation of the interrelationship between articular cartilage and trabecular bone of the osteoarthritic knee. Osteoarthritis Cartilage. 2004 Feb 2004;12(2):86-96.

20. Lo GH, Zhang Y, McLennan C, et al. The ratio of medial to lateral tibial plateau bone mineral density and compartment-specific tibiofemoral osteoarthritis. Osteoarthritis Cartilage. Oct 2006;14(10):984-990.

21. Kellgren JH, Lawrence JS. Radiological assessment of osteo-arthrosis. Ann Rheum Dis. Dec 1957;16(4):494-502.

22. Burstein D, Gray ML. Is MRI fulfilling its promise for molecular imaging of cartilage in arthritis? Osteoarthritis Cartilage. 2006 Aug 72006.

23. Wilson DR, Apreleva MV, Eichler MJ, Harrold FR. Accuracy and repeatability of a pressure measurement system in the patellofemoral joint. J Biomech. 2003 Dec 2003;36(12):1909-1915.

24. Radin EL, Ehrlich MG, Chernack R, Abernethy P, Paul IL, Rose RM. Effect of repetitive impulsive loading on the knee joints of rabbits. Clin Orthop Relat Res. Mar-Apr 1978(131):288-293.

25. Song Y, Greve JM, Carter DR, Koo S, Giori NJ. Articular cartilage MR imaging and thickness mapping of a loaded knee joint before and after meniscectomy. Osteoarthritis Cartilage. Aug 2006;14(8):728-737.

26. Pan B, Wu DF, Wang ZY. Internal displacement and strain measurement using digital volume correlation: a least-squares framework. Meas Sci Technol. Apr 2012;23(4).

27. Banerjee $P, M c L e a n C R$. Femoroacetabular impingement: a review of diagnosis and management. Current reviews in musculoskeletal medicine. 2011;4(1):23-32.

28. Leunig M, Beaule PE, Ganz R. The concept of femoroacetabular impingement: current status and future perspectives. Clin Orthop Relat Res. Mar 2009;467(3):616-622.

29. Ahmed AM, Burke DL, Yu A. In-vitro measurement of static pressure distribution in synovial joints-Part II: Retropatellar surface. J Biomech Eng. 1983 Aug 1983;105(3):226-236.

30. Ahmed AM, Duncan NA. Correlation of patellar tracking pattern with trochlear and retropatellar surface topographies. J Biomech Eng. 2000 Dec 2000;122(6):652-660.

31. Ahmed AM, Duncan NA, Tanzer M. In vitro measurement of the tracking pattern of the human patella. J Biomech Eng. 1999 Apr 1999;121(2):222-228.

32. Huberti HH, Hayes WC. Contact pressures in chondromalacia patellae and the effects of capsular reconstructive procedures. J Orthop Res. 1988 1988;6(4):499-508.

33. Huberti $\mathrm{HH}$, Hayes WC. Patellofemoral contact pressures. The influence of $\mathrm{q}$-angle and tendofemoral contact. J Bone Joint Surg Am. 1984 Jun 1984;66(5):715-724.

34. Ateshian GA, Kwak SD, Soslowsky LJ, Mow VC. A stereophotogrammetric method for determining in situ contact areas in diarthrodial joints, and a comparison with other methods. J Biomech. 1994 Jan 1994;27(1):111-124.

35. Brown TD, Shaw DT. In vitro contact stress distributions in the natural human hip. J Biomech. 1983;16(6):373-384.

36. Apreleva M, Hasselman CT, Debski RE, Fu FH, Woo SL, Warner JJ. A dynamic analysis of glenohumeral motion after simulated capsulolabral injury. A cadaver model. J Bone Joint Surg Am. Apr 1998;80(4):474-480.

37. Blankevoort L, Huiskes R. Validation of a three-dimensional model of the knee. J Biomech. 1996 Jul 1996;29(7):955-961.

38. Elias JJ, Wilson DR, Adamson R, Cosgarea AJ. Evaluation of a computational model used to predict the patellofemoral contact pressure distribution. J Biomech. 2004 Mar 2004;37(3):295-302.

39. Wismans J, Veldpaus F, Janssen J, Huson A, Struben P. A three-dimensional mathematical model of the knee-joint. J Biomech. 1980 1980;13(8):677-685. 
40. Blankevoort L, Kuiper JH, Huiskes R, Grootenboer HJ. Articular contact in a three-dimensional model of the knee. J Biomech. 1991 1991;24(11):1019-1031.

41. van der Helm FC. A finite element musculoskeletal model of the shoulder mechanism. J Biomech. May 1994;27(5):551-569.

42. Brown TD, DiGioia AM, 3rd. A contact-coupled finite element analysis of the natural adult hip. $J$ Biomech. 1984;17(6):437-448.

43. Ahmad CS, Kwak SD, Ateshian GA, Warden WH, Steadman JR, Mow VC. Effects of patellar tendon adhesion to the anterior tibia on knee mechanics. The American journal of sports medicine. 1998 Sep-Oct 1998;26(5):715-724.

44. Kwak SD, Ahmad CS, Gardner TR, et al. Hamstrings and iliotibial band forces affect knee kinematics and contact pattern. J Orthop Res. 2000 Jan 2000;18(1):101-108.

45. Cohen ZA, Henry JH, McCarthy DM, Mow VC, Ateshian GA. Computer simulations of patellofemoral joint surgery. Patient-specific models for tuberosity transfer. The American journal of sports medicine. 2003 Jan-Feb 2003;31(1):87-98.

46. Cohen ZA, Roglic H, Grelsamer RP, et al. Patellofemoral stresses during open and closed kinetic chain exercises. An analysis using computer simulation. The American journal of sports medicine. 2001 Jul-Aug 2001;29(4):480-487.

47. Hadley NA, Brown TD, Weinstein SL. The effects of contact pressure elevations and aseptic necrosis on the long-term outcome of congenital hip dislocation. J Orthop Res. Jul 1990;8(4):504513.

48. McErlain DD, Milner JS, Ivanov TG, Jencikova-Celerin L, Pollmann SI, Holdsworth DW. Subchondral cysts create increased intra-osseous stress in early knee OA: A finite element analysis using simulated lesions. Bone. Mar 1 2011;48(3):639-646.

49. van Lenthe GH, Muller R. Prediction of failure load using micro-finite element analysis models: Towards in vivo strength assessment. Drug Discovery Today: Technologies. 2006;3(2):221-229.

50. Helgason B, Perilli E, Schileo E, Taddei F, Brynjolfsson S, Viceconti M. Mathematical relationships between bone density and mechanical properties: a literature review. Clin Biomech (Bristol, Avon). Feb 2008;23(2):135-146.

51. Samosky JT, Burstein D, Eric Grimson W, Howe R, Martin S, Gray ML. Spatially-localized correlation of dGEMRIC-measured GAG distribution and mechanical stiffness in the human tibial plateau. $J$ Orthop Res. 2005 Jan 2005;23(1):93-101.

52. MacNeil JA, Boyd SK. Bone strength at the distal radius can be estimated from high-resolution peripheral quantitative computed tomography and the finite element method. Bone. Jun 2008;42(6):1203-1213.

53. Keyak JH, Rossi SA. Prediction of femoral fracture load using finite element models: an examination of stress- and strain-based failure theories. J Biomech. Feb 2000;33(2):209-214.

54. Bay BK. Methods and applications of digital volume correlation. J Strain Anal Eng. Nov 2008;43(8):745-760.

55. Kanamiya $T$, Naito $M$, Hara $M$, Yoshimura I. The influences of biomechanical factors on cartilage regeneration after high tibial osteotomy for knees with medial compartment osteoarthritis: clinical and arthroscopic observations. Arthroscopy : the journal of arthroscopic \& related surgery : official publication of the Arthroscopy Association of North America and the International Arthroscopy Association. 2002 Sep 2002;18(7):725-729.

56. Ito K, Minka MAn, Leunig M, Werlen S, Ganz R. Femoroacetabular impingement and the cameffect. A MRI-based quantitative anatomical study of the femoral head-neck offset. $J$ Bone Joint Surg Br. 2001 Mar 2001;83(2):171-176.

57. Morrison JB. The mechanics of the knee joint in relation to normal walking. $J$ Biomech. Jan 1970;3(1):51-61. 
58. Li K, Zheng L, Tashman S, Zhang X. The inaccuracy of surface-measured model-derived tibiofemoral kinematics. J Biomech. Oct 11 2012;45(15):2719-2723.

59. Andriacchi TP, Alexander EJ, Toney MK, Dyrby C, Sum J. A point cluster method for in vivo motion analysis: applied to a study of knee kinematics. J Biomech Eng. Dec 1998;120(6):743-749.

60. D'Lima DD, Fregly BJ, Patil S, Steklov N, Colwell CW. Knee joint forces: prediction, measurement, and significance. Proceedings of the Institution of Mechanical Engineers, Part H: Journal of Engineering in Medicine. 2012;226(2):95-102.

61. Cleather DJ, Bull AM. The development of lower limb musculoskeletal models with clinical relevance is dependent upon the fidelity of the mathematical description of the lower limb. Part 2: patient-specific geometry. Proceedings of the Institution of Mechanical Engineers, Part H: Journal of Engineering in Medicine. 2012;226(2):133-145.

62. Delport HP, Banks SA, De Schepper J, Bellemans J. A kinematic comparison of fixed- and mobilebearing knee replacements. J Bone Joint Surg Br. Aug 2006;88(8):1016-1021.

63. Kanisawa I, Banks AZ, Banks SA, Moriya H, Tsuchiya A. Weight-bearing knee kinematics in subjects with two types of anterior cruciate ligament reconstructions. Knee surgery, sports traumatology, arthroscopy : official journal of the ESSKA. Jan 2003;11(1):16-22.

64. Amiri S, Anglin C, Agbanlog K, Masri BA, Wilson DR. A model-free feature-based bi-planar RSA method for kinematic analysis of total knee arthroplasty. J Biomech Eng. Mar 2012;134(3):031009.

65. Karrholm J, Brandsson S, Freeman MA. Tibiofemoral movement 4: changes of axial tibial rotation caused by forced rotation at the weight-bearing knee studied by RSA. J Bone Joint Surg Br. Nov 2000;82(8):1201-1203.

66. Fleming BC, Peura GD, Abate JA, Beynnon BD. Accuracy and repeatability of Roentgen stereophotogrammetric analysis (RSA) for measuring knee laxity in longitudinal studies. J Biomech. Oct 2001;34(10):1355-1359.

67. Martin DE, Greco NJ, Klatt BA, Wright VJ, Anderst WJ, Tashman S. Model-based tracking of the hip: implications for novel analyses of hip pathology. J Arthroplasty. Jan 2011;26(1):88-97.

68. Fox AM, Kedgley AE, Lalone EA, Johnson JA, Athwal GS, Jenkyn TR. The effect of decreasing computed tomography dosage on radiostereometric analysis (RSA) accuracy at the glenohumeral joint. J Biomech. Nov 10 2011;44(16):2847-2850.

69. You BM, Siy P, Anderst W, Tashman S. In vivo measurement of 3-D skeletal kinematics from sequences of biplane radiographs: application to knee kinematics. IEEE Trans Med Imaging. Jun 2001;20(6):514-525.

70. Goyal K, Tashman S, Wang JH, Li K, Zhang X, Harner C. In vivo analysis of the isolated posterior cruciate ligament-deficient knee during functional activities. The American journal of sports medicine. Apr 2012;40(4):777-785.

71. Anderst WJ, Tashman S. A method to estimate in vivo dynamic articular surface interaction. $J$ Biomech. 2003 Sep 2003;36(9):1291-1299.

72. Anderst W, Zauel R, Bishop J, Demps E, Tashman S. Validation of three-dimensional model-based tibio-femoral tracking during running. Medical engineering \& physics. Jan 2009;31(1):10-16.

73. Bey MJ, Zauel R, Brock SK, Tashman S. Validation of a new model-based tracking technique for measuring three-dimensional, in vivo glenohumeral joint kinematics. J Biomech Eng. Aug 2006;128(4):604-609.

74. Brossmann J, Muhle C, Schroder C, et al. Patellar tracking patterns during active and passive knee extension: evaluation with motion-triggered cine MR imaging. Radiology. $1993 \mathrm{Apr}$ 1993;187(1):205-212.

75. Salsich GB, Ward SR, Terk MR, Powers CM. In vivo assessment of patellofemoral joint contact area in individuals who are pain free. Clin Orthop. 2003 Dec 2003(417):277-284. 
76. Draper CE, Besier TF, Fredericson M, et al. Differences in patellofemoral kinematics between weight-bearing and non-weight-bearing conditions in patients with patellofemoral pain. J Orthop Res. Oct 14 2010; In Press.

77. Draper CE, Santos JM, Kourtis LC, et al. Feasibility of using real-time MRI to measure joint kinematics in 1.5T and open-bore 0.5T systems. J Magn Reson Imaging. Jul 2008;28(1):158-166.

78. Powers CM, Ward SR, Fredericson M, Guillet M, Shellock FG. Patellofemoral kinematics during weight-bearing and non-weight-bearing knee extension in persons with lateral subluxation of the patella: a preliminary study. J Orthop Sports Phys Ther. 2003 Nov 2003;33(11):677-685.

79. von Eisenhart-Rothe R, Siebert M, Bringmann C, Vogl T, Englmeier KH, Graichen H. A new in vivo technique for determination of $3 \mathrm{D}$ kinematics and contact areas of the patello-femoral and tibiofemoral joint. J Biomech. 2004 Jun 2004;37(6):927-934.

80. Muhle C, Brossmann J, Heller M. Kinematic CT and MR imaging of the patellofemoral joint. Eur Radiol. 1999 1999;9(3):508-518.

81. Fellows RA, Hill NA, Gill HS, et al. Magnetic resonance imaging for in vivo assessment of threedimensional patellar tracking. J Biomech. 2005 Aug 2005;38(8):1643-1652.

82. Fellows RA, Hill NA, Macintyre NJ, Harrison MM, Ellis RE, Wilson DR. Repeatability of a novel technique for in vivo measurement of three-dimensional patellar tracking using magnetic resonance imaging. J Magn Reson Imaging. 2005 Jul 2005;22(1):145-153.

83. Patel VV, Hall K, Ries $M$, et al. Magnetic resonance imaging of patellofemoral kinematics with weight-bearing. J Bone Joint Surg Am. 2003 Dec 2003;85-A(12):2419-2424.

84. Kaiser J, Bradford R, Johnson K, Wieben O, Thelen DG. Measurement of tibiofemoral kinematics using highly accelerated $3 \mathrm{D}$ radial sampling. Magnetic resonance in medicine : official journal of the Society of Magnetic Resonance in Medicine / Society of Magnetic Resonance in Medicine. Jun 122012.

85. d'Entremont AG, Nordmeyer-Massner JA, Bos C, Wilson DR, Pruessmann KP. Do dynamic-based MR knee kinematics methods produce the same results as static methods? Magnetic resonance in medicine : official journal of the Society of Magnetic Resonance in Medicine / Society of Magnetic Resonance in Medicine. Jul 272012.

86. Sheehan FT, Drace JE. Quantitative MR measures of three-dimensional patellar kinematics as a research and diagnostic tool. Med Sci Sports Exerc. 1999 Oct 1999;31(10):1399-1405.

87. Sheehan FT, Zajac FE, Drace JE. Using cine phase contrast magnetic resonance imaging to noninvasively study in vivo knee dynamics. J Biomech. 1998 Jan 1998;31(1):21-26.

88. Sheehan FT, Zajac FE, Drace JE. In vivo tracking of the human patella using cine phase contrast magnetic resonance imaging. J Biomech Eng. 1999 Dec 1999;121(6):650-656.

89. Barrance PJ, Williams GN, Novotny JE, Buchanan TS. A method for measurement of joint kinematics in vivo by registration of 3-D geometric models with cine phase contrast magnetic resonance imaging data. J Biomech Eng. Oct 2005;127(5):829-837.

90. Rebmann AJ, Sheehan FT. Precise 3D skeletal kinematics using fast phase contrast magnetic resonance imaging. J Magn Reson Imaging. 2003 Feb 2003;17(2):206-213.

91. Lerner AL, Tamez-Pena JG, Houck JR, et al. The use of sequential MR image sets for determining tibiofemoral motion: reliability of coordinate systems and accuracy of motion tracking algorithm. J Biomech Eng. Apr 2003;125(2):246-253.

92. Barrance PJ, Williams GN, Snyder-Mackler L, Buchanan TS. Do ACL-injured copers exhibit differences in knee kinematics?: An MRI study. Clin Orthop Relat Res. Jan 2007;454:74-80.

93. Barrance PJ, Williams GN, Snyder-Mackler L, Buchanan TS. Altered knee kinematics in ACLdeficient non-copers: a comparison using dynamic MRI. J Orthop Res. Feb 2006;24(2):132-140.

94. Patel VV, Hall K, Ries M, et al. A three-dimensional MRI analysis of knee kinematics. J Orthop Res. 2004 Mar 2004;22(2):283-292. 
95. Draper CE, Besier TF, Santos JM, et al. Patellofemoral kinematic differences exist between highload and low-load conditions in patients with patellofemoral pain. Paper presented at: American Society of Biomechanics Annual Meeting2009; State College, PA, USA.

96. McWalter EJ, Hunter DJ, Wilson DR. The effect of load magnitude on three-dimensional patellar kinematics in vivo. J Biomech. Jul 20 2010;43(10):1890-1897.

97. Besier TF, Draper CE, Gold GE, Beaupre GS, Delp SL. Patellofemoral joint contact area increases with knee flexion and weight-bearing. J Orthop Res. 2005 Mar 2005;23(2):345-350.

98. Gold GE, Besier TF, Draper CE, Asakawa DS, Delp SL, Beaupre GS. Weight-bearing MRI of patellofemoral joint cartilage contact area. J Magn Reson Imaging. 2004 Sep 2004;20(3):526-530.

99. Heino Brechter J, Powers CM, Terk MR, Ward SR, Lee TQ. Quantification of patellofemoral joint contact area using magnetic resonance imaging. Magn Reson Imaging. 2003 Nov 2003;21(9):955959.

100. Hinterwimmer S, Gotthardt M, von Eisenhart-Rothe $R$, et al. In vivo contact areas of the knee in patients with patellar subluxation. J Biomech. 2005 Oct 2005;38(10):2095-2101.

101. Hinterwimmer S, von Eisenhart-Rothe R, Siebert M, Welsch F, Vogl T, Graichen H. Patella kinematics and patello-femoral contact areas in patients with genu varum and mild osteoarthritis. Clin Biomech (Bristol, Avon). 2004 Aug 2004;19(7):704-710.

102. Nakagawa S, Kadoya Y, Kobayashi A, Tatsumi I, Nishida N, Yamano Y. Kinematics of the patella in deep flexion. Analysis with magnetic resonance imaging. J Bone Joint Surg Am. 2003 Jul 2003;85$A(7): 1238-1242$.

103. Powers CM, Ward SR, Chan LD, Chen YJ, Terk MR. The effect of bracing on patella alignment and patellofemoral joint contact area. Med Sci Sports Exerc. 2004 Jul 2004;36(7):1226-1232.

104. Ward SR, Powers CM. The influence of patella alta on patellofemoral joint stress during normal and fast walking. Clin Biomech (Bristol, Avon). Dec 2004;19(10):1040-1047.

105. Ward SR, Terk MR, Powers CM. Patella alta: association with patellofemoral alignment and changes in contact area during weight-bearing. J Bone Joint Surg Am. Aug 2007;89(8):1749-1755.

106. Connolly KD, Ronsky JL, Westover LM, Kupper JC, Frayne R. Differences in patellofemoral contact mechanics associated with patellofemoral pain syndrome. J Biomech. Dec 11 2009;42(16):28022807.

107. Shin CS, Carpenter RD, Majumdar S, Ma CB. Three-dimensional in vivo patellofemoral kinematics and contact area of anterior cruciate ligament-deficient and -reconstructed subjects using magnetic resonance imaging. Arthroscopy : the journal of arthroscopic \& related surgery : official publication of the Arthroscopy Association of North America and the International Arthroscopy Association. Nov 2009;25(11):1214-1223.

108. Lalone EA, McDonald CP, Ferreira LM, Peters TM, King GW, Johnson JA. Development of an imagebased technique to examine joint congruency at the elbow. Computer methods in biomechanics and biomedical engineering. Jan 132012.

109. Borotikar BS, Sipprell WH, 3rd, Wible EE, Sheehan FT. A methodology to accurately quantify patellofemoral cartilage contact kinematics by combining 3D image shape registration and cinePC MRI velocity data. J Biomech. Apr 5 2012;45(6):1117-1122.

110. Hosseini A, Van de Velde S, Gill TJ, Li G. Tibiofemoral cartilage contact biomechanics in patients after reconstruction of a ruptured anterior cruciate ligament. J Orthop Res. Nov 2012;30(11):1781-1788.

111. Subburaj $K$, Souza RB, Stehling $C$, et al. Association of MR relaxation and cartilage deformation in knee osteoarthritis. J Orthop Res. Jun 2012;30(6):919-926.

112. Shin CS, Souza RB, Kumar D, Link TM, Wyman BT, Majumdar S. In vivo tibiofemoral cartilage-tocartilage contact area of females with medial osteoarthritis under acute loading using MRI. J Magn Reson Imaging. Dec 2011;34(6):1405-1413. 
113. Yao J, Lancianese SL, Hovinga KR, Lee J, Lerner AL. Magnetic resonance image analysis of meniscal translation and tibio-menisco-femoral contact in deep knee flexion. J Orthop Res. May 2008;26(5):673-684.

114. Yao J, Salo AD, Lee J, Lerner AL. Sensitivity of tibio-menisco-femoral joint contact behavior to variations in knee kinematics. J Biomech. 2008;41(2):390-398.

115. Connolly KD, Ronsky JL, Westover LM, Kupper JC, Frayne R. Analysis techniques for congruence of the patellofemoral joint. J Biomech Eng. Dec 2009;131(12):124503.

116. McWalter EJ, O'Kane CO, FitzPatrick DP, Wilson DR. Validation of an MRI-based method to assess patellofemoral joint contact areas in loaded knee flexion in vivo. J Magn Reson Imaging. 2012;Accepted.

117. Goto A, Moritomo H, Murase T, et al. In vivo elbow biomechanical analysis during flexion: threedimensional motion analysis using magnetic resonance imaging. J Shoulder Elbow Surg. Jul-Aug 2004;13(4):441-447.

118. Lalone EA, Peters TM, King GW, Johnson JA. Accuracy assessment of an imaging technique to examine ulnohumeral joint congruency during elbow flexion. Computer aided surgery : official journal of the International Society for Computer Aided Surgery. 2012;17(3):142-152.

119. Chan DD, Neu CP, Hull ML. Articular cartilage deformation determined in an intact tibiofemoral joint by displacement-encoded imaging. Magnetic resonance in medicine : official journal of the Society of Magnetic Resonance in Medicine / Society of Magnetic Resonance in Medicine. Apr 2009;61(4):989-993.

120. Chan DD, Neu CP, Hull ML. In situ deformation of cartilage in cyclically loaded tibiofemoral joints by displacement-encoded MRI. Osteoarthritis Cartilage. Nov 2009;17(11):1461-1468.

121. Greaves LL, Gilbart MK, Yung A, Kozlowski P, Wilson DR. Deformation and recovery of cartilage in the intact hip under physiological loads using 7T MRI. J Biomech. Feb 9 2009;42(3):349-354.

122. Halder A, Kutzner I, Graichen F, Heinlein B, Beier A, Bergmann G. Influence of limb alignment on mediolateral loading in total knee replacement: in vivo measurements in five patients. J Bone Joint Surg Am. Jun 6 2012;94(11):1023-1029.

123. Felson DT. Osteoarthritis as a disease of mechanics. Osteoarthritis Cartilage. Oct 42012.

124. Laxafoss E, Jacobsen S, Gosvig KK, Sonne-Holm S. The alignment of the knee joint in relationship to age and osteoarthritis : The Copenhagen Osteoarthritis Study. Skeletal radiology. Sep 112012.

125. Reid SM, Graham RB, Costigan PA. Differentiation of young and older adult stair climbing gait using principal component analysis. Gait \& posture. Feb 2010;31(2):197-203.

126. Cahue S, Dunlop D, Hayes K, Song J, Torres L, Sharma L. Varus-valgus alignment in the progression of patellofemoral osteoarthritis. Arthritis Rheum. 2004 Jul 2004;50(7):2184-2190.

127. Elahi S, Cahue S, Felson DT, Engelman L, Sharma L. The association between varus-valgus alignment and patellofemoral osteoarthritis. Arthritis Rheum. Aug 2000;43(8):1874-1880.

128. Harrison MM, Cooke TD, Fisher SB, Griffin MP. Patterns of knee arthrosis and patellar subluxation. Clin Orthop Relat Res. 1994 Dec 1994(309):56-63.

129. Sharma L. The role of proprioceptive deficits, ligamentous laxity, and malalignment in development and progression of knee osteoarthritis. J Rheumatol Suppl. 2004 Apr 2004;70:87-92.

130. Sharma L, Song J, Felson DT, Cahue S, Shamiyeh E, Dunlop DD. The role of knee alignment in disease progression and functional decline in knee osteoarthritis. JAMA. Jul 11 2001;286(2):188195.

131. Sharma L, Eckstein F, Song J, et al. Relationship of meniscal damage, meniscal extrusion, malalignment, and joint laxity to subsequent cartilage loss in osteoarthritic knees. Arthritis Rheum. Jun 2008;58(6):1716-1726.

132. Hunter DJ, Niu J, Felson DT, et al. Knee alignment does not predict incident osteoarthritis: the Framingham osteoarthritis study. Arthritis Rheum. Apr 2007;56(4):1212-1218. 
133. Felson DT, Goggins J, Niu J, Zhang Y, Hunter DJ. The effect of body weight on progression of knee osteoarthritis is dependent on alignment. Arthritis Rheum. Dec 2004;50(12):3904-3909.

134. Niu J, Zhang YQ, Torner J, et al. Is obesity a risk factor for progressive radiographic knee osteoarthritis? Arthritis Rheum. Mar 15 2009;61(3):329-335.

135. Moisio K, Chang A, Eckstein F, et al. Varus-valgus alignment: reduced risk of subsequent cartilage loss in the less loaded compartment. Arthritis Rheum. Apr 2011;63(4):1002-1009.

136. Cerejo R, Dunlop DD, Cahue S, Channin D, Song J, Sharma L. The influence of alignment on risk of knee osteoarthritis progression according to baseline stage of disease. Arthritis Rheum. 2002 Oct 2002;46(10):2632-2636.

137. Williams A, Sharma L, McKenzie CA, Prasad PV, Burstein D. Delayed gadolinium-enhanced magnetic resonance imaging of cartilage in knee osteoarthritis: findings at different radiographic stages of disease and relationship to malalignment. Arthritis Rheum. 2005 Nov 2005;52(11):35283535 .

138. Friedrich KM, Shepard T, Chang G, et al. Does joint alignment affect the $T 2$ values of cartilage in patients with knee osteoarthritis? Eur Radiol. Jun 2010;20(6):1532-1538.

139. Kalichman L, Zhang $\mathrm{Y}$, Niu J, et al. The association between patellar alignment on magnetic resonance imaging and radiographic manifestations of knee osteoarthritis. Arthritis Res Ther. 2007;9(2):R26.

140. Kalichman $L$, Zhang $Y$, Niu J, et al. The association between patellar alignment and patellofemoral joint osteoarthritis features--an MRI study. Rheumatology (Oxford). Aug 2007;46(8):1303-1308.

141. Kalichman $L$, Zhu $Y$, Zhang $Y$, et al. The association between patella alignment and knee pain and function: an MRI study in persons with symptomatic knee osteoarthritis. Osteoarthritis Cartilage. Nov 2007;15(11):1235-1240.

142. Hunter DJ, Zhang YQ, Niu JB, et al. Patella malalignment, pain and patellofemoral progression: the Health ABC Study. Osteoarthritis Cartilage. Oct 2007;15(10):1120-1127.

143. Stefanik JJ, Zhu Y, Zumwalt AC, et al. Association between patella alta and the prevalence and worsening of structural features of patellofemoral joint osteoarthritis: the multicenter osteoarthritis study. Arthritis care \& research. Sep 2010;62(9):1258-1265.

144. Gross KD, Niu J, Stefanik JJ, et al. Breaking the Law of Valgus: the surprising and unexplained prevalence of medial patellofemoral cartilage damage. Ann Rheum Dis. Nov 2012;71(11):18271832.

145. McAlindon $\mathrm{T}$, Zhang $\mathrm{Y}$, Hannan $\mathrm{M}$, et al. Are risk factors for patellofemoral and tibiofemoral knee osteoarthritis different? J Rheumatol. Feb 1996;23(2):332-337.

146. Cicuttini FM, Spector T, Baker J. Risk factors for osteoarthritis in the tibiofemoral and patellofemoral joints of the knee. J Rheumatol. Jun 1997;24(6):1164-1167.

147. Cooper C, McAlindon T, Snow S, et al. Mechanical and constitutional risk factors for symptomatic knee osteoarthritis: differences between medial tibiofemoral and patellofemoral disease. $J$ Rheumatol. 1994 Feb 1994;21(2):307-313.

148. Hunter DJ, Zhang $\mathrm{Y}, \mathrm{Niu} J$, et al. Structural factors associated with malalignment in knee osteoarthritis: the Boston osteoarthritis knee study. J Rheumatol. Nov 2005;32(11):2192-2199.

149. Zhang $Y$, Hunter DJ, Nevitt MC, et al. Association of squatting with increased prevalence of radiographic tibiofemoral knee osteoarthritis: the Beijing Osteoarthritis Study. Arthritis Rheum. Apr 2004;50(4):1187-1192.

150. Englund $M$, Lohmander LS. Patellofemoral osteoarthritis coexistent with tibiofemoral osteoarthritis in a meniscectomy population. Ann Rheum Dis. Dec 2005;64(12):1721-1726.

151. Hunter DJ, Niu J, Zhang Y, et al. Knee height, knee pain, and knee osteoarthritis: the Beijing Osteoarthritis Study. Arthritis Rheum. May 2005;52(5):1418-1423. 
152. Baliunas $A J$, Hurwitz $D E$, Ryals $A B$, et al. Increased knee joint loads during walking are present in subjects with knee osteoarthritis. Osteoarthritis Cartilage. 2002 Jul 2002;10(7):573-579.

153. Foroughi N, Smith R, Vanwanseele B. The association of external knee adduction moment with biomechanical variables in osteoarthritis: a systematic review. The Knee. Oct 2009;16(5):303-309.

154. Mundermann A, Dyrby CO, Hurwitz DE, Sharma L, Andriacchi TP. Potential strategies to reduce medial compartment loading in patients with knee osteoarthritis of varying severity: reduced walking speed. Arthritis Rheum. 2004 Apr 2004;50(4):1172-1178.

155. Maly MR, Robbins SM, Stratford PW, Birmingham TB, Callaghan JP. Cumulative knee adductor load distinguishes between healthy and osteoarthritic knees-A proof of principle study. Gait \& posture. Sep 172012.

156. Mundermann A, Dyrby CO, Andriacchi TP. Secondary gait changes in patients with medial compartment knee osteoarthritis: increased load at the ankle, knee, and hip during walking. Arthritis Rheum. Sep 2005;52(9):2835-2844.

157. Astephen JL, Deluzio KJ, Caldwell GE, Dunbar MJ, Hubley-Kozey CL. Gait and neuromuscular pattern changes are associated with differences in knee osteoarthritis severity levels. J Biomech. 2008;41(4):868-876.

158. Hurwitz DE, Hulet $\mathrm{CH}$, Andriacchi TP, Rosenberg AG, Galante JO. Gait compensations in patients with osteoarthritis of the hip and their relationship to pain and passive hip motion. $J$ Orthop Res. Jul 1997;15(4):629-635.

159. McGibbon CA, Krebs DE. Compensatory gait mechanics in patients with unilateral knee arthritis. J Rheumatol. Nov 2002;29(11):2410-2419.

160. Chang A, Hayes K, Dunlop D, et al. Hip abduction moment and protection against medial tibiofemoral osteoarthritis progression. Arthritis Rheum. Nov 2005;52(11):3515-3519.

161. Shakoor N, Hurwitz DE, Block JA, Shott S, Case JP. Asymmetric knee loading in advanced unilateral hip osteoarthritis. Arthritis Rheum. Jun 2003;48(6):1556-1561.

162. Creaby MW, Bennell KL, Hunt MA. Gait differs between unilateral and bilateral knee osteoarthritis. Arch Phys Med Rehabil. May 2012;93(5):822-827.

163. Chang $A$, Hurwitz $D$, Dunlop $D$, et al. The relationship between toe-out angle during gait and progression of medial tibiofemoral osteoarthritis. Ann Rheum Dis. Oct 2007;66(10):1271-1275.

164. Anderson DD, Marsh JL, Brown TD. The pathomechanical etiology of post-traumatic osteoarthritis following intraarticular fractures. The lowa orthopaedic journal. 2011;31:1-20.

165. Lohmander LS, Englund PM, Dahl LL, Roos EM. The long-term consequence of anterior cruciate ligament and meniscus injuries: osteoarthritis. The American journal of sports medicine. Oct 2007;35(10):1756-1769.

166. Englund M, Joud A, Geborek P, Felson DT, Jacobsson LT, Petersson IF. Prevalence and incidence of rheumatoid arthritis in southern Sweden 2008 and their relation to prescribed biologics. Rheumatology (Oxford). Aug 2010;49(8):1563-1569.

167. Crema MD, Roemer FW, Felson DT, et al. Factors Associated with Meniscal Extrusion in Knees with or at Risk for Osteoarthritis: The Multicenter Osteoarthritis Study. Radiology. Aug 2012;264(2):494-503.

168. Englund M, Felson DT, Guermazi A, et al. Risk factors for medial meniscal pathology on knee MRI in older US adults: a multicentre prospective cohort study. Ann Rheum Dis. Oct 2011;70(10):17331739.

169. Englund M, Guermazi A, Gale D, et al. Incidental meniscal findings on knee MRI in middle-aged and elderly persons. New England Journal of Medicine. 2008;359(11):1108-1115.

170. Englund M, Guermazi A, Roemer FW, et al. Meniscal pathology on MRI increases the risk for both incident and enlarging subchondral bone marrow lesions of the knee: the MOST Study. Ann Rheum Dis. Oct 2010;69(10):1796-1802. 
171. Lohmander LS, Felson D. Can we identify a 'high risk' patient profile to determine who will experience rapid progression of osteoarthritis? Osteoarthritis Cartilage. 2004;12 Suppl A:S49-52.

172. von Porat A, Roos EM, Roos H. High prevalence of osteoarthritis 14 years after an anterior cruciate ligament tear in male soccer players: a study of radiographic and patient relevant outcomes. Ann Rheum Dis. Mar 2004;63(3):269-273.

173. Amin S, Guermazi A, Lavalley MP, et al. Complete anterior cruciate ligament tear and the risk for cartilage loss and progression of symptoms in men and women with knee osteoarthritis. Osteoarthritis Cartilage. Aug 2008;16(8):897-902.

174. Hernandez-Molina G, Guermazi A, Niu J, et al. Central bone marrow lesions in symptomatic knee osteoarthritis and their relationship to anterior cruciate ligament tears and cartilage loss. Arthritis Rheum. Jan 2008;58(1):130-136.

175. Chaudhari AM, Briant PL, Bevill SL, Koo S, Andriacchi TP. Knee kinematics, cartilage morphology, and osteoarthritis after ACL injury. Med Sci Sports Exerc. Feb 2008;40(2):215-222.

176. Harris WH. Etiology of osteoarthritis of the hip. Clin Orthop. 1986 Dec 1986(213):20-33.

177. Imam S, Khanduja V. Current concepts in the diagnosis and management of femoroacetabular impingement. International orthopaedics. Oct 2011;35(10):1427-1435.

178. Beck M, Kalhor M, Leunig M, Ganz R. Hip morphology influences the pattern of damage to the acetabular cartilage: femoroacetabular impingement as a cause of early osteoarthritis of the hip. J Bone Joint Surg Br. 2005 Jul 2005;87(7):1012-1018.

179. Beck M, Leunig M, Parvizi J, Boutier V, Wyss D, Ganz R. Anterior femoroacetabular impingement: part II. Midterm results of surgical treatment. Clin Orthop. 2004 Jan 2004(418):67-73.

180. Bardakos NV, Villar RN. Predictors of progression of osteoarthritis in femoroacetabular impingement: a radiological study with a minimum of ten years follow-up. J Bone Joint Surg Br. Feb 2009;91(2):162-169.

181. Pollard TC, McNally EG, Wilson DC, et al. Localized cartilage assessment with three-dimensional dGEMRIC in asymptomatic hips with normal morphology and cam deformity. J Bone Joint Surg Am. Nov 3 2010;92(15):2557-2569.

182. Reichenbach $S$, Juni $P$, Werlen $S$, et al. Prevalence of cam-type deformity on hip magnetic resonance imaging in young males: a cross-sectional study. Arthritis care \& research. Sep 2010;62(9):1319-1327.

183. Laborie LB, Lehmann TG, Engesaeter IO, Eastwood DM, Engesaeter LB, Rosendahl K. Prevalence of radiographic findings thought to be associated with femoroacetabular impingement in a population-based cohort of 2081 healthy young adults. Radiology. Aug 2011;260(2):494-502.

184. COVENTRY MB. OSTEOTOMY OF THE UPPER PORTION OF THE TIBIA FOR DEGENERATIVE ARTHRITIS OF THE KNEE. A PRELIMINARY REPORT. J Bone Joint Surg Am. 1965 Jul 1965;47:984990.

185. Wakabayashi S, Akizuki S, Takizawa T, Yasukawa Y. A comparison of the healing potential of fibrillated cartilage versus eburnated bone in osteoarthritic knees after high tibial osteotomy: An arthroscopic study with 1-year follow-up. Arthroscopy : the journal of arthroscopic \& related surgery: official publication of the Arthroscopy Association of North America and the International Arthroscopy Association. 2002 Mar 2002;18(3):272-278.

186. Odenbring $\mathrm{S}$, Egund $\mathrm{N}$, Lindstrand $\mathrm{A}$, Lohmander $\mathrm{LS}$, Willen $\mathrm{H}$. Cartilage regeneration after proximal tibial osteotomy for medial gonarthrosis. An arthroscopic, roentgenographic, and histologic study. Clin Orthop. 1992 Apr 1992(277):210-216.

187. Ng VY, Arora N, Best TM, Pan X, Ellis TJ. Efficacy of surgery for femoroacetabular impingement: a systematic review. The American journal of sports medicine. Nov 2010;38(11):2337-2345.

188. Clohisy JC, St John LC, Schutz AL. Surgical treatment of femoroacetabular impingement: a systematic review of the literature. Clin Orthop Relat Res. Feb 2010;468(2):555-564. 
189. Reeves ND, Bowling FL. Conservative biomechanical strategies for knee osteoarthritis. Nature reviews. Rheumatology. Feb 2011;7(2):113-122.

190. Rinonapoli E, Mancini GB, Corvaglia A, Musiello S. Tibial osteotomy for varus gonarthrosis. A 10to 21-year followup study. Clin Orthop. 1998 Aug 1998(353):185-193.

191. A WD, Robertsson O, Lohmander LS. High tibial osteotomy in Sweden, 1998-2007: a populationbased study of the use and rate of revision to knee arthroplasty. Acta orthopaedica. Jun 2012;83(3):244-248.

192. Bennell KL, Creaby MW, Wrigley TV, Hunter DJ. Tibial subchondral trabecular volumetric bone density in medial knee joint osteoarthritis using peripheral quantitative computed tomography technology. Arthritis Rheum. Sep 2008;58(9):2776-2785. 